Revista da Associação Portuguesa de Sociologia

\title{
A pesquisa sociológica em contextos de pobreza
}

\section{João Matheus Acosta Dallmann ${ }^{1}$}

\begin{abstract}
Resumo: Neste artigo elaboro algumas reflexões acerca do trabalho de investigação sociológica em contextos de pobreza. A partir do estado da arte da temática no Brasil e França, busco esboçar possibilidades críticas para o avanço da pesquisa sociológica sobre pobreza e exclusão social no século XXI. Com base nos referenciais teóricos actuais, problematizo e reflicto acerca da importancia da sociologia da pobreza para as sociedades contemporâneas, em especial para o Brasil.
\end{abstract}

Palavras-chave: investigação sociológica, técnicas de pesquisa, pobreza, sociologia da pobreza.

\section{The sociological research on poverty context}

\begin{abstract}
In this article I make some reflections about the sociological research work on poverty contexts. From the state of the theme in Brazil and France, I seek to outline critical possibilities to the advance of sociological research on poverty and social exclusion in the 21 st century. Having current theoretical references as a basis, I problematize and reflect about the importance of sociology of poverty to the contemporary societies, mainly in Brazil.
\end{abstract}

Keywords: sociological research, research techniques, poverty, sociology of poverty.

Este artigo pretende esboçar algumas técnicas de pesquisa no campo da chamada sociologia da pobreza. A partir da obra do sociólogo Serge Paugam (2005, 2015) pretende-se analisar a experiência da pobreza em seu caráter multidimensional. Assim, compreende-se que a vivência na pobreza não pode ser descrita de forma homogênea, tal como acontece em muitos trabalhos de viés quantitativo, pelo contrário, a estatística deve ser um preâmbulo ao trabalho científico, contribuindo na formulação de problemas e hipóteses. Para refletir sobre a especificidade da pesquisa

\footnotetext{
${ }^{1}$ Universidade Federal de Santa Catarina/Brasil, departamento de Sociologia Política e Departamento de Medicina da Universidade Federal de Santa Catarina/Brasil. João Dallmann é bacharel em Ciências Sociais pela Universidade Federal de Santa Catarina. Mestre em Sociologia Política pela UFSC. Doutorando do Programa de Pós-graduação em Sociologia Política pela mesma Universidade. Pesquisas nas áreas de Sociologia da Pobreza com enfase nos Programas de Transferência Condicionada de Renda (PTCR), principalmente o Programa Bolsa Família (PBF) no Brasil, e, nos estudos sobre medicalização da pobreza e da infância em políticas sociais. É membro do Núcleo de Estudos em Sociologia, Filosofia e História das Ciências (NESFHIS), acostadallmann@gmail.com.
} 
com populações pobres pretende-se estabelecer uma argumentação que apresenta as formulações de Paugam como eixo articulador de três trabalhos de cientistas sociais brasileiros.

Abrimos este artigo com uma pequena exposição da história da sociologia da pobreza, a partir dela, principalmente através da influência de Georg Simmel, se desenvolveram trabalhos importantes para a pesquisa com populações pobres. Neste sentido, expomos o caminho teórico para a definição daquilo que constituiu, do ponto de vista sociológico, as categorias "pobre e pobreza". Partindo da suposição de que a experiência na pobreza é singular, isto é, que os indivíduos pobres a vivenciam de maneiras muito distintas em contextos próprios. Percorreremos, então, por uma breve definição de tipos ideais no interior da pobreza. $\mathrm{O}$ estabelecimento desses tipos ideais sugere que as discussões sobre o fenômeno da pobreza precisam incorporar as variadas dimensões e articulações que os agentes fazem na/da vida cotidiana. Assumindo esse ponto de partida, percorremos pela ideia de que a pesquisa, que na sua concretude é a interação entre pesquisador e pesquisado, é uma prática social, uma prática de intensa negociação entre os sujeitos, um jogo de sentidos discursivos. Desse modo, é a partir da análise de trabalhos realizados no Brasil entre os anos 1990 e 2013 que descrevemos e problematizamos a importância das configurações singulares no seio das camadas mais empobrecidas. Essas configurações singulares são apreendidas a partir do subsídio teórico de Paugam, que mesmo num contexto cultural e geográfico diferente, estabelece um caminho metodológico interessante para nossas pesquisas.

Em suma, este artigo, explorando a ideia de que a pobreza possui diversas facetas que são diferentemente vivenciadas em nosso país, propõe uma abordagem de investigação multifacetada do fenômeno. Parte-se da ideia que a pobreza não é mera falta de recursos monetários, mas antes é uma posição social relacional, isto é, relativa em cada contexto, difusa e complexa no seu próprio interior.

\section{Surgimento da sociologia da pobreza}

Pode-se dizer que a sociologia da pobreza inicia em 1907 com o famoso texto do sociólogo alemão Georg Simmel Der Arme (1907) ou O pobre (1998), como ficou 
conhecido na Europa e nos Estados Unidos - um ensaio metodológico cujo objetivo era refletir a capacidade articuladora de um determinado fenómeno. Para o autor o pobre enquanto uma categoria social, não pode ser, de um ponto de vista sociológico, aqueles que sofrem carências ou privações de várias ordens, é antes, a figura que toda a sociabilidade de um contexto específico constrói e oferece assistência. Em suma, se considerar o pobre enquanto a personificação de um sujeito diogenesiano ${ }^{2}$, o pesquisador não conseguirá apreender as redes de significações que se articulam na construção deste grupo social. A pobreza, então, não pode ser somente constatada através da quantificação da renda monetária, nem somente da percepção do próprio pesquisador que imbuído de boa vontade elabora uma personagem exótica e heroica. Tal abordagem construtivista da pobreza romperia com as concepções naturalistas e substancialistas de finais do século XIX, incrustadas nos debates políticos e científicos ${ }^{3}$ dando um caráter sociológico para tal questão social.

Robert Castel é outro autor incontornável nesta área problemática, pelo trabalho que empreendeu para compreender as formas de exclusão e pobreza do século XX. As suas contribuições a partir da França reverberaram por toda a sociologia das desigualdades sociais nas Américas. No seu clássico Les métamorfoses de la question sociale (1995) Castel assume uma postura crítica e afirma que a "nova questão social" é paradoxalmente oposta ao sujeito considerado pobre para a sociologia de Simmel. Nesta os sujeitos considerados pobres são aqueles que recebem assistência social, seja aquela vinda do Estado (via políticas sociais) seja a provinda da caridade particular. No entanto, para Castel o neoliberalismo construiu o que o autor descreve como individualismo negativo, isto é, o isolamento social de indivíduos extremamente desconectados do mundo do trabalho, aqueles cuja vida nas franjas mais (des)socializadas da sociedade é um éden. Desse modo, as camadas pobres ou extremamente pobres desprovidas de qualquer tipo de tutela ou contrato, integrarão a análise sociológica da exclusão e das desigualdades. Tal sociologia da pobreza deve, de certo modo, compreender o seu caráter formulador de problemas e por consequência, formulador de hipóteses e respostas.

2 Relativo a Diógenes que na Antiguidade Clássica fora um homem extremamente pobre vivendo nas ruas cercado somente por cachorros.

3 Sobre esse assunto ver: PAUGAM, S; SHULTEIS, F (1998). Naissance d'une sociologie de la pauvreté. In:Simmel, Georg (1998), Les Pauvres, Paris, Presses Universitaires de France.. 
No Brasil Anete Ivo, socióloga e autora de Viver por um fio: pobreza e políticas sociais (2008), analisa a construção do Estado social na América Latina. Aqui, seguindo a mesma linha de Castel, o pobre enquanto categoria sociológica é aquele cuja "vida por um fio" está a mercê de um Estado social, que nunca se emancipa e mesmo durante a gestação se desmantela com políticas neoliberais. Nessa linha, o risco e as incertezas sobre a vida material culminam no fim da coesão social da era salarial (Castel, 1995, 2004), cujo maior impacto se dá na organização sócio-política dos trabalhadores e trabalhadoras. Agora, cada vez mais submetido à flexibilização das relações laborais, o pobre é aquele cuja biografia circula entre o abismo e o perau ${ }^{4}$, nem reconhecido pelo Estado nem totalmente liberto. Judicializado, medicalizado, criminalizado, o pobre se torna o foco de uma sociedade de incertezas (la montée d'incertitudes), no entanto, não se trata de focalizar para (re)socializar, senão que, para controlar através de inúmeros dispositivos sem os quais a governamentalidade, esse neologismo foucaultiano, seria impossível ${ }^{5}$.

Em suma, nosso caminho argumentativo constituirá em articular as três percepções, evidenciando, tal como demonstra Serge Paugam (2005, 2015), as possibilidades de compreendermos a figura do pobre enquanto uma categoria social distribuída em "formas elementares"6. Essa paráfrase ao livro de Emile Durkheim que mais nos remete a ideia de continuidade temporal na evolução das categorias explicativas é, pelo contrário, a elaboração de tipos ideais que nos auxiliam a construir uma realidade explicativa do mundo social, seja através das falas dos pesquisados (o evidente, o aparente, a linguagem), seja por meio da escrita do etnógrafo (sua percepção, o não dito, o olhar). Talvez por isso a transcrição da entrevista, prova de fidelidade do pesquisador com o pesquisado, tenha assumido um lugar de destaque no campo da sociologia da pobreza com os trabalhos de Pierre Bourdieu (2003, 2007) e Loïc Wacquant (2003, 2011). Considerados construtivistas críticos, embora tenham ido além das fronteiras disciplinares, para os autores a "fala dos sujeitos" assume a responsabilidade de

\footnotetext{
${ }^{4}$ Perau: subida íngreme tipicamente encontrada em bairros populares e favelas brasileiras.

${ }^{5}$ Michel Foucault trata desse tema na aula de 14 de março de 1979 In: Foucault, Michel (2008), O Nascimento da biopolitica, São Paulo, Martins Fontes..

${ }^{6}$ Adiante nas páginas posteriores irei discutir e reelaborar, a ideia em contextos de pesquisa empírica.
} 
reconstruir no texto o mundo social dos pesquisados.

Assim, este trabalho pretende discutir e refletir brevemente sobre as práticas da etnografia, da entrevista e da abordagem quantitativa nas pesquisas sociológicas (ou próximas a tal abordagem) sobre a pobreza. Sem o intuito de valorar quais destas perspectivas metodológicas estão corretas ou erradas, pretendemos ao dar prioridade ao objeto, colocar em perspectiva as contribuiçõoes e as limitações de cada técnica, de modo que, possa-se desenhar uma constelação acerca da própria categoria, em outras palavras, compreender que a cognição não pode apreender a realidade em sua total imediaticidade, e o que descrevemos como conteúdo objetivo de nossa percepção científica sobre as práticas sociais, é, antes de qualquer coisa, um movimento abstrato de construção literária.

\section{A construção de tipos ideais para compreender a pobreza no Brasil contemporâneo}

Os estudos sobre pobreza e transferência de renda no Brasil contemporâneo têm galgado cada dia mais espaço nas publicações acadêmicas. Fruto, primordialmente, da experiência do Programa Bolsa Família, as pesquisas desenvolvidas nos últimos 15 anos tem problematizado a pobreza desde diferentes perspectivas. Nesta reflexão iremos aderir a perspectiva de Serge Paugam (2005) porque consideramos que suas formulações nos auxiliam a compreender a multidimensionalidade da pobreza, bem como nos incitam a novas problemáticas de pesquisa sobre o tema no Brasil. A partir das reflexões sociológicas de Tocqueville, Marx, Simmel e sua própria pesquisa na França, Canadá, Estados Unidos e países da América Latina, o autor quer compreender e problematizar as representações sociais, experiências e laços sociais dos pobres. No entanto, o autor não centra sua análise somente na figura dos pobres e dos imigrantes, para fazer uma sociologia da pobreza é necessário interrogar o sistema social em sua amplitude, levar em conta as formas de proteção contra a proximidade dos pobres criadas pelas elites, por exemplo. Para isso desenvolve a ideia de formas elementares da pobreza. Essa ideia singular busca compreender os mecanismos de geração/manutenção da pobreza e as respostas políticas ao fenômeno, por isso, divide em três principais tipos ideais a pobreza contemporânea, a saber: a pobreza integrada, a pobreza marginalizada e a pobreza 
desqualificada.

A pobreza integrada é resultado da expansão e da reorganização da proteção social no início do século XXI. Diz-se integrada porque a estes pobres, tal como na concepção simmeliana, a assistência do Estado aparece na forma de transferência condicionada de renda, isto é, são pobres porque são assistidos e reconhecidos enquanto tal. A este tipo ideal agregam-se os trabalhadores pobres, aqueles cuja integração ao mercado de trabalho se dá por meio de empregos precários, baixos salários, jornadas duplas e triplas, etc. O segundo tipo de pobreza que, a modo de análise, planteia Paugam é o da pobreza marginalizada. Ela é caracterizada pela ruptura dos laços sociais, o não acesso aos bens e serviços públicos de todas as ordens, ela é dependente da caridade privada e precisa reforçar sempre a necessidade de auxílio, isto é, depende da performance para ser vista como tal. Em suma, os pobres marginalizados não estão integrados nas relações sociais de trabalho, família, amigos, etc., são e se consideram indignos, inúteis para a sociedade $\left(\right.$ Souza, 2009) ${ }^{7}$. A pobreza considerada desqualificada está marcada pela ideia de estigma, igual ao primeiro tipo, onde os indivíduos recebem assistência social via transferência monetária direta. Nessa categoria os pobres são fruto da frágil coesão social e da visão preconceituosa com relação às políticas públicas. Estigmatizados, alvo de preconceito e discriminação, estes pobres incorporam a culpa por estarem pobres, sentem vergonha pelo fato de serem assistidos. Como se isso não bastasse, também se tornam alvo de um legislativo que a todo o momento tenta criar um princípio de less iligibility (menos elegibilidade) no interior da transferência monetária. Um exemplo problemático deste princípio é a proposta que tramitou no parlamento brasileiro em 2014, em que os direitos políticos dos beneficiários do programa Bolsa Família seriam suspensos até que não precisassem mais do benefício.

O estabelecimento destas categorias não se dá no intuito de rotular os trabalhos que aqui serão analisados, eles servem para problematizarmos a suposta homogeneidade com que se tratam os dados quantitativos e qualitativos quando o tema é a pobreza. Ainda

\footnotetext{
7 Os trabalhos de Jessé Souza inovam na construção de categorias explicativas. Em 2009 criou o termo "batalhadores" ou "classe batalhadora", para designar a distribuição desigual de renda no interior das chamadas camadas médias ou populares.
} 
assim, cada caso é um caso $^{8}$, ou seja, é imprescindível que pensemos a articulação dessas experiências por parte das populações estudadas. Por conseguinte, cada articulação levanos a uma nova problemática, cada categoria isolada ou não, traz-nos um conjunto de práticas sociais interligadas que formam/conformam nosso objeto. Por isso, por exemplo, não há somente pobreza desqualificada se não houver nesse recorte populacional pobreza integrada. Desse modo, se dois tipos ideais se articulam e coexistem como no exemplo, significa que, neste caso, existe integração desigual ou, que em outros casos existe uma paulatina marginalização. Por fim, não se tratará de universalizar as categorias com as quais iremos analisar os textos, mas, de alguma forma, criar uma dimensão sociológica explicativa aos problemas estudados.

\section{A pesquisa como prática social}

A visibilidade ou invisibilidade da pobreza é um constructo social e político que, via de regra, depende da organização sócio espacial da cidade, isto é, do espaço urbano. Nele habitam as condições que possibilitam a sociabilidade das mais diversificadas formas/performances de pobreza, por isso, dá um panorama da desigualdade num sentido relacional. Daí advém uma gama de problemas sociológicos, a incluir-se um primeiro que diz respeito à problematização da cidade. A cidade, esse aglomerado urbano, denso demograficamente, desigual na circulação de bens e serviços, não homogeneíza, e, isso deve ficar claro ao pesquisador. Ao passo que ela é um espaço social diversificado é, também, para uns com mais força para outros com menos, significado de repressão, intolerância, formas de controlo, mas ainda assim de negociação, agencia, etc. Em virtude disso, existe no interior das cidades um aglomerado de interiores, periféricos, marginalizados, esquecidos, que não habitam/disfrutam a mesma distribuição de capitais. O espaço urbano é, portanto, e sobretudo, uma "invenção social”, como nos indica Roberto da Matta (1991). Isso parece óbvio a princípio, mas no desdobramento de muitas pesquisas tendemos ao final objetivar as privações de certas populações por meio de

\footnotetext{
8 Ver Fonseca, Claúdia (1999) “Quando cada caso não é um caso: a etnografia nas pesquisas em educação”, Revista brasileira de educação, 10: 58-78.
} 
nossos próprios padrões de consumo. Por isso, afirmamos que a pesquisa, aqui corporificada na entrevista, é uma prática social que a todo instante precisa ser problematizada pelo pesquisador.

Nesta linha de raciocínio escolhemos por discutir e, logo, problematizar alguns trabalhos. Daremos ênfase à construção de seus objetos, as técnicas empregadas e aos resultados obtidos. Desse modo, teremos um pequeno grupo de abordagens sobre o tema pobreza a partir das ciências sociais. Logo, o recorte de textos foi sem a preocupação de buscar certas regularidades, mas com o intuito de colocar em perspectiva trabalhos diferentes entre si, trabalhos estes que são extremamente relevantes para compreender o Brasil contemporâneo. Sendo assim, escolhemos A ralé brasileira-Quem é e como vive de Jessé Souza (2009), Viração - Experiências de meninos na rua de Maria Filomena Gregori (2000) e Vozes do Bolsa Família - Autonomia, dinheiro e cidadania de Rego e Pinzani (2013). Temporalmente distantes, geograficamente desiguais, cremos que estes trabalhos possam dar um panorama das pesquisas sobre pobreza no Brasil.

\section{Ralé}

Quem se autodenominaria ralé? Por trás da vergonha de assumir-se pobre não estaria escondido um conjunto de práticas discriminatórias? Em outras palavras, se existe pobreza no Brasil contemporâneo ela certamente é tão heterogênea como a população em nosso território nacional. Jessé Souza em seu livro propõe uma análise não clássica da sociabilidade do brasileiro precarizado. Souza não partirá de um "mal de origem”, nem fará uma radiografia estatística para provar sua hipótese de pesquisa, irá propor, a partir da crítica ferrenha ao quantitativismo, uma análise sociológica do presente cuja perspectiva metodológica é interdisciplinar. Souza elaborará seu trabalho - com um conjunto de autores - passando pela filosofia, história, etnografia, estatística, ciência política, etc.

Logo de partida é preciso definir qual o objeto teórico elaborado pelo autor, a que se deve a suspensão da ideia de classe no interior do debate de classes, bem como nas discussões sobre estratificação social no Brasil. Esse questionamento de Jessé Souza se fundamenta na persistência da pobreza como um fenómeno naturalizado na história brasileira. Nas suas palavras: 
O processo de modernização brasileiro constitui não apenas as novas classes sociais modernas que se apropriam diferencialmente dos capitais cultural e econômico. Ele constitui também uma classe inteira de indivíduos, não só sem capital cultural nem econômico em qualquer medida significativa, mas desprovida, esse é o aspecto fundamental, das precondições sociais, morais e culturais que permitem essa apropriação. É essa classe social que designamos neste livro de "ralé" estrutural, não para "ofender" essas pessoas já tão sofridas e humilhadas, mas para chamar a atenção, provocativamente, para nosso maior conflito social e político: o abandono social e político, "consentido por toda a sociedade”, de toda uma classe de indivíduos "precarizados" que se reproduz há gerações enquanto tal. Essa classe social, que é sempre esquecida enquanto uma classe com uma gênese e um destino comum, só é percebida no debate público como um conjunto de "indivíduos" carentes ou perigosos, tratados fragmentariamente por temas de discussão superficiais, dado que nunca chegam sequer a nomear o problema real, tais como "violência”, "segurança pública”, "problema da escola pública”, "carência da saúde pública”, "combate à fome” etc. (Souza, 2009, pp. 21)

Neste sentido, Souza e sua equipe de pesquisa querem desvelar o "Brasil para além do mito", isto é, sem deixar de lado a produção do pensamento social brasileiro, mas, fundamentando-se no aspecto multiparadigmático da pesquisa com populações e fenômenos tão diversos. Este aspecto multiparadigmático está ressaltado na linguagem do texto, nas abordagens, nos termos, nas escolhas metodológicas. Desse modo, sua pesquisa pode problematizar as "mulheres da ralé", os "homens da ralé", a "má-fé institucional" e o racismo no Brasil, porque, segundo o autor "qualquer método ou técnica de pesquisa tem de se adequar ao 'objeto' ou 'interesse' particular de pesquisa ao qual ele serve" (Souza, 2009, pp. 80).

Bom, vimos que a construção do objeto de pesquisa neste trabalho seguiu uma lógica que busca nas práticas sociais de um dado contexto as linhas de fissura, como nos ensinou Deleuze, os aspectos que são obscurecidos ou relegados à pesquisa de caso. Essa "classe de indivíduos" é quantitativamente expressiva e qualitativamente alcançável ao pesquisador. Como ressalta Souza, uma pesquisa crítica deve primar por seu objeto 
mesmo que isso se dê em detrimento da técnica de interesse do pesquisador. Por exemplo, o "fetiche do número" mesmo nas pesquisas qualitativas deve ser desfeito em prol da profundidade com que são realizadas as entrevistas, provém daí as sutilezas que podem subsidiar novos objetos de investigação. Sendo assim, não há no livro de Souza predileção por um determinado método, e isso para nossa reflexão é de extrema importância, o autor interpreta a "realidade brasileira" a partir da crítica às interpretações clássicas ou neoclássicas, por meio de entrevistas em profundidade e entrevistas dirigidas (survey), inclusive sugere criticar, e o faz, as suas próprias pesquisas. Nesse empreendimento científico, Souza quer fazer emergir a ação dos agentes na constituição de suas visões de mundo (por isso dedica um capítulo à crítica de um autor quantitativista), sem a consciência de que os indivíduos constroem discursos singulares, o pesquisador, inexoravelmente enviesa a "resposta" do campo antagonizando o dissonante que se sobressai, as contradições, as lacunas, o próprio comportamento do pesquisado (Souza, 2009, pp. 435).

\section{Viração}

Quantas vezes já ouvimos no ambiente acadêmico alguém consternado com a situação de alguma população considerada pobre, sem meios para sobreviver, desprovida de qualquer capacidade cognitiva ou política de fazer escolhas ou se expressar? Ao questionarmos o interesse por essas populações ou grupo de indivíduos a resposta é quase sempre a mesma, - Quero dar voz a esses sujeitos! Imbuídos destes sentimentos alguns colegas se lançam a uma cruzada contra a pobreza e, ao final, acabam por culpabilizar os sujeitos pobres por sua situação.

Essa pequena digressão serve para ilustrar a sobredeterminação encontrada por Maria Filomena Gregori em sua pesquisa com meninos nas ruas de São Paulo. De acordo com Gregori, há um senso comum de que a criança na rua está "fora do lugar". Esse "fora do lugar" significa que está fora de casa, da companhia de seus pais e, por isso, critica dessa conclusão Gregori quer demonstrar que os "meninos de rua" podem ilustrar a "forma vigorosa e trágica [dos] dilemas sociais, políticos e morais da sociedade brasileira" (Gregori, 2000, pp. 15). Para a autora é inegável a persistência da pobreza como um fator 
fundamental na proliferação de crianças em situação de rua. No entanto, é preciso evitar as explicações causais que, no intuito de dar um caráter científico à explicação dos problemas, não permitem evidenciar as experiências e o universo material e simbólico em que se constitui a vida na rua.

Neste caso, a escolha de Gregori foi pela etnografia. Realizada entre os anos de 1991 e 2000, a pesquisa empreendeu esforços em compreender as práticas de diferentes grupos de crianças na rua, bem como, as práticas dos agentes institucionais a eles destinadas. A autora considera a importância da estatística, mas, ressalta que neste contexto de rua a imprecisão estatística é muito acentuada. Como exemplo dessa afirmação, ela escreve que até 1980 o número de crianças na rua variava de 10 mil a 7 milhões. Com a etnografia, a autora pode colocar em dialogo as práticas dos diferentes agentes institucionais e suas visões sobre a vida nas ruas, nesta interação textual evidencia-se um tipo social de criança de rua. Tal tipo social ainda não é suficientemente explicativo para a autora.

Diante disso, não aceitando nenhuma explicação casuística, a autora "deixa" emergir um termo que se transformará num mote explicativo. O termo viração é empregado para descrever e problematizar a prática de "se virar", "uma noção exemplar para descrever o processo singular das experiências travadas pelos meninos de rua" (Gregori, 2000, pp. 18). Decorre daí um panorama sobre as diferentes imagens produzidas por eles, por suas leituras do mundo, pela efetividade de sua performance no mundo social e nas práticas concretas. "Suas experiências são importantes porque permitem o estudo de processos extremamente dinâmicos de constituição de identidade" (Gregori, 2000, pp. 19).

Esta etnografia serve-nos como exemplo profícuo para a ideia de pobreza marginalizada. Desprovida de qualquer meio pelo qual possa aceder aos bens públicos (emprego, salário, transporte, etc.), eles precisam "se virar" como podem para obter o mínimo necessário, vejam que não é o mínimo estipulado por grupo A ou B e, sim, aquilo que eles acreditam ser o básico para sua sobrevivência. Desse modo, o singular que se evidencia com as entrevistas em profundidade realizadas por Gregori, complexifica nossa noção de fala, de discurso, isto é, coloca-nos a possibilidade de problematizar os enunciados coletivos e individuais através da compreensão de como se constroem tais identidades. Ao narrar experiências individuais, tomando-as como biografias exemplares, 
a autora toca numa questão crucial ao dilema brasileiro.

Não é exagerado afirmar que essa trama institucional - mais do que uma malha ou uma rede - passa a alimentar os aspectos singulares das experiências dos meninos de rua: a viração e a circulação. De modo paradoxal, em vez de romper com este circuito e ajudá-los a construir um projeto de futuro, o mau relacionamento entre os agentes de intervenção resulta em uma situação em que o menino é transformado em objeto de disputa, alvo de conflitos. Circulando entre os vários organismos, se virando, ele sobrevive e se protege. Mas está longe de conseguir projetar um caminho de saída da menoridade. Seu destino permanece na circularidade das ações. Parece condenado a ser, para sempre, um menino de rua. (Gregori, 2000, pp. 53)

\section{Jequitinhonha}

Inúmeras investigações sociais são produzidas sobre a pobreza tornando-se um tema bastante amplo do ponto de vista metodológico. No entanto, existem poucos trabalhos em que a "voz dos pobres" é transcrita e tomada com seriedade, essa é a perspectiva de Walquiria Leão Rego e Alessandro Pinzani no seu livro Vozes do Bolsa Família: Autonomia, dinheiro e cidadania. A partir do universo material e simbólico dos pobres no Vale do Jequitinhonha, os autores tratam da transferência de renda pelo viés da experiência de "receber". Através da articulação entre autonomia, dinheiro e cidadania, eles contestam e problematizam a luta contra a pobreza, o fim do coronelismo, o efeito do dinheiro sobre o cotidiano das mulheres beneficiárias, entre muitos outros temas que se desdobram nas mais de 50 entrevistas realizadas.

Para resgatar uma tradição de pesquisa social pela chamada Teoria Crítica da Sociedade, Pinzani elabora reflexões metodológicas acerca da relação sujeito/objeto, um tema bastante importante para a sociologia alemã. Nessa linha, Pinzani discute pressupostos epistemológicos que levam os pesquisadores a não refletir seu papel na pesquisa qualitativa. Para o autor, existe na esfera académica certa postura inconsciente de "eliminação do pobre", tal como nas palavras de Simmel, isto é, quanto maior é o abismo social que separa o pesquisador do pesquisado, menor é o tempo que se dedica à escuta e à fala destes sujeitos. 
Consequentemente, maior é a possibilidade de estigmatizar, romantizar, enviesar o "resultado" do trabalho.

No que se refere à forma pela qual se desenvolveram os trabalhos de Rego e Pinzani, a escolha dos autores foi por fazer uma etnografia longa (cinco anos), com entrevistas em profundidade e análise documental (textos, jornais, legislação, propostas de lei, discursos oficiais do Governo Federal). A partir da filosofia do dinheiro de Georg Simmel, levantam hipóteses sobre o significado simbólico e material dos bens de consumo para os pobres daquele contexto específico. Desse modo, percorrendo a fala dos sujeitos, os autores, intercalam reflexão teórica com discursos que emergem no campo. Para corroborar algumas das teses da obra ainda lançam mão de dados quantitativos, que são interpretados à luz da experiência de campo.

O objeto teórico, essa construção que habita entre o cotidiano que se busca compreender e as ferramentas teóricas que se tem para explicar, delimita-se através da interação dos pobres com o Programa Bolsa Família, em outras palavras, Rego e Pinzani tomam por objeto a construção de uma "nova sociabilidade" nos contextos de pobreza extrema, lugares onde "nunca antes na história deste país" havia chegado nenhum tipo de proteção social. Embora, cheguem à conclusão de que paulatinamente a luta contra a pobreza tem vencido os ciclos intergeracionais de exclusão social, os autores ressaltam que ainda milhões de brasileiros vivem sob a miséria, "completamente fora das heranças básicas da civilização" (Rego \& Pinzani, 2013, pp. 220).

Diferente dos trabalhos anteriormente expostos neste artigo, em Vozes do Bolsa Família encontramos uma articulação entre três categorias/conceitos que segundo os autores são chaves para a superação da pobreza. A autonomia ao receber uma transferência direta de renda vai desenvolvendo no interior dessas camadas um sentimento de pertencimento ao mundo, o conceito que utilizam é o de empowerment ou empoderamento. Este é notório principalmente para as mulheres: muitas delas nunca haviam estado com dinheiro em suas mãos, quem diria um cartão magnético. A titularidade restrita às mulheres, no caso do Bolsa Família, é para Rego um passo para a luta contra a violência de género e o machismo. Na voz das mulheres, são elas quem melhor gerem a renda familiar e, por isso, é através delas que a "mudança" de vida deve iniciar. Como vemos, a autonomia deriva da 
renda (dinheiro), ao ter acesso ao dinheiro os beneficiários podem decidir sobre a utilização, sobre como, onde e quando empregá-lo. Nos tempos da cesta básica2 não se podia escolher os itens, era muito restrito a um mito alimentício, nele proteína + proteína era sinónimo de boa saúde. Em suma, o dinheiro "na mão" dessas mulheres transforma o cotidiano e coloca no jogo social novas possibilidades de ação individual e conjunta. Bom, mas somente a transferência de renda possibilita a cidadania? Certamente, não. O maior entrave, e, talvez, um dos resultados mais originais desta pesquisa, é a falta de autorrespeito dessas populações pobres, que advém da interiorização de uma imagem criada pelo outro. Retroalimentada nos meios de comunicação, nas ações do Estado, nos serviços públicos através de alguns agentes preconceituosos, a pobreza desqualificada, ou a desqualificação social dos pobres, se dá pela ideia de que todo o indivíduo deve responsabilizar-se por sua situação económica sem que ninguém, nem mesmo o Estado, tenha de interferir para ajudalo. A imagem de que pobre é pobre porque quer, porque não busca trabalho, se constrói e alimenta o ódio à pobreza que vivemos na atualidade. Os autores descobriram em seu campo um sentimento de vergonha e de reproche ao benefício, um entrave para uma cidadania ativa.

\section{Consciência comum, consciência erudita}

No parlamento brasileiro quando vemos o embate discursivo que se estabelece no que se refere a temas como a pobreza, a violência de gênero, a menoridade penal, o aborto, podemos concluir, basicamente que o conteúdo das elaborações políticas que se efetivam em propostas de lei é resultante de um senso de responsabilidade com o mundo baseado em pré-noções de sentido comum, salvo algumas exceções. Decorre daí, que os termos da vida cotidiana impõem-se como evidências que o sociólogo precisa e deve questionar. Portanto, é comum que todo estudo sobre a pobreza parta de uma posição de incómodo sobre o mundo social, mas, como bem escreveu Bourdieu (1992), esse incómodo (problema social) deve transformar-se em um problema sociológico, caso contrário será somente sociologia espontânea.

Nos três trabalhos acima resenhados podemos observar de maneira consistente a construção da pobreza enquanto um problema sociológico. Viu-se a necessidade de 
questionar a própria noção de pobreza, o raciocínio binário que opõe as características dos pobres às dos ricos, bem como a arbitrariedade em quantificar os pobres a partir de uma linha monetária. Sendo assim, em todos os textos o objeto de estudo por excelência não é, portanto, a pobreza, nem os pobres quantificados, como um fenómeno social substancializado, mas, a relação de interdependência entre eles e a sociedade como um todo. Nesta passagem, de um problema social (a existência de pobres) para um problema sociológico (as relações sociais entre os diferentes estratos da população), que hora parece um fato simplório, temos o surgimento de um arcabouço de possibilidades para pesquisar o tema. Assim, não mais nos interessa a falta de meios para sobreviver, mas, por exemplo, os mecanismos de designação dos pobres nas diferentes sociedades, as experiências concretas em relação aos diferentes programas sociais, a evolução das taxas de pobreza e a delimitação dos índices (sempre problematizados) e por ai vai. Em suma, ao tratarmos a pobreza, enquanto um problema sociológico, devemos estar alertas às tentações da sociologia espontânea.

Mesmo munidos de um vocabulário explicativo, precisamos problematizar o próprio uso dos termos que empregamos como nos alerta Lahire (1999), ao lançarmos de alguns conceitos como os de "mundo social", "grupo social", "origem social", é necessário que não os utilizemos como fontes explicativas, casuísticas. Esse descolamento da teoria à realidade, mecanismo que implica uma boa retórica, esconde as possibilidades, tanto nas pesquisas quantitativas, quanto nas qualitativas, de evidenciarmos aquilo que está subtraído das generalizações, dos grandes surveys. "Deslocando o olhar [...] para a singularidade evidente de qualquer caso a partir do momento em que se consideram as coisas no detalhe, o sociólogo mostra aquilo que os modelos teóricos fundados no conhecimento estatístico e na linguagem das variáveis ignoravam” (Lahire, 1999, pp. 32), em outras palavras, é imprescindível heterogeneizar o homogeneizado nas explicações sociológicas não contextualizadas.

Sendo assim, nenhum sociólogo deve ignorar a complexidade das categorias pobre e pobreza. Em qualquer circunstância é inexoravelmente necessário contextualizar a construção do seu objeto cujo tema é a pobreza. Isso não significa dedicar linhas e linhas num ritual quase religioso para descrever a "história" da pobreza no mundo, é, antes de qualquer coisa, explicitar onde a construção do objeto se coloca na configuração social na qual vivem os pesquisados e o pesquisador. Cada configuração social obedece a especificidades 
interacionais e dão vazão a uma gama de particularidades. Essas particularidades não podem ser vistas somente como adornos típicos de sociabilidades menos complexas, mesmo descritas densamente elas podem/devem ter um caráter explicativo. "Por querer dizer tudo e considerar tudo como significante, os sociólogos às vezes perdem a noção de estruturação dos seus objetos de pesquisa" (Lahire, 1999, pp. 41). Baseado nesta noção estrutural Paugam (2005, 2015), como já vimos anteriormente, estabelece que no interior daquilo que consideramos pobre ou pobreza, devemos possibilitar o surgimento de especificidades que tornam a categoria subdividida em razão das experiências que se vivenciam. É simples, nem todos os pobres vivenciam/experienciam a pobreza da mesma forma, nem numa mesma sociedade, muito menos em contextos culturais e políticos diferentes.

No trabalho de Pinzani e Rego (2013) a noção de desqualificação social aparece junto à ideia de pobreza integrada. Isto porque, a desqualificação social é um processo de mudança no perfil da assistência ao longo das décadas, essa mudança empurra as camadas populares mais vulneráveis às franjas sociais que, paulatinamente, perdem o acesso ao emprego e, consequentemente, a seguridade social. Desse modo, a experiência da pobreza, que pode ser apreendida nos três textos, conjuga fragilidade internalizada (vergonha, falta de autorrespeito), fragilidade negociada (os testes de meios, o cumprimento de obrigatoriedades para receber um beneficio, o atestado de pobreza), a espera pela assistência (no Brasil temos o Cadastro único de programas sociais, cadastrado neste sistema o candidato ao beneficio, enquanto espera, deve manter-se dentro dos limites monetários de pobreza) e dispositivos de repressão à organização para reivindicar (a criminalização da luta por moradia é um dos exemplos possíveis). Assim, a experiência da pobreza é moldada a partir do jogo entre a estratificação social e a construção socio-política das instituições cuja função é a assistência social. Destarte, o estatuto social de pobre se constituiu num campo de embate político que está sempre atrelado à economia e a governamentalidade.

Nesse mesmo caminho, a pobreza, numa perspectiva metodológica, assume ainda mais três formas: a fragilidade (diferente da anterior), a dependência e a ruptura dos laços sociais. Os meninos na rua, que vivem a experiência da viração e da circulação entre instituições, estão certamente vivendo sob frágeis laços sociais, onde sobretudo "estar vivo" conta. Eles perderam os laços familiares, o vinculo com a escola e, por inúmeras razões, têm receio à 
assistência. A assistência, essa instituição do Estado social, é personificada pelos agentes responsáveis por suas ações práticas, sendo essas ações em muitos casos repressiva, moralista, como descrito por Gregori (2000), Rego e Pinzani (2013), ao contrário de reintegrar elas caminham entre a dependência e a ruptura dos laços.

Um aspecto muito importante na configuração de uma política social, que mais bem é um programa como no caso do Bolsa Família, é a experiência da dependência. Em razão de circular na opinião publica a ideia de acomodação dos pobres, muitos trabalhos no âmbito das humanidades têm ressaltado a agencia dos beneficiários e suas lutas pela superação dos ciclos intergeracionais de pobreza. Rego e Pinzani (2013) assim também procedem em sua etnografia. No entanto, se ousassem criticar o partido buscariam a compreensão da dependência, esse aspecto fundador da assistência, nos dispositivos que constituem a participação em um programa social. Em outras palavras, esses dispositivos (um deles é o impedimento de obter remuneração fixa com carteira assinada) empurram os trabalhadores pobres aos empregos mais precários. Submetidos a essas configurações, a dependência é uma prática do Estado e não uma ação do indivíduo.

\section{Considerações finais}

Em que medida, o depoimento dos pobres transcrito pelo pesquisador não é, também, a construção de uma memória coletiva? Aquilo que neste artigo chamamos de narrativas particulares, de singularidades do homogeneizado, ao transformar-se em texto através do filtro do autor é, de certa maneira, uma ação política necessária, mas antes, é uma indagação à sociedade: Se vivemos sob a égide da civilização, por que ainda é necessário evidenciar injustiças sociais? Nosso intuito com esse texto é o de refletir sobre abordagens metodológicas, mas também, mostrar como elas remontam problemas significativos e urgentes. A escolha da técnica ou do método em todos os casos descritos obedeceu a um mesmo critério, melhor compreender as formas elementares e particularizadas da experiência na pobreza, indispensável num país continental.

Em síntese, é esse o ponto que devemos priorizar, isto é, todas as técnicas de pesquisa precisam ser empregadas para melhor conhecer os objetos, as práticas sociais, a limitação a uma determinada abordagem causa-nos cegueira intelectual, uma cegueira que nos 
proporciona um conhecimento medíocre, pré-estabelecido, indubitavelmente desimportante para o desenvolvimento de uma sociedade. A proposta de reflexão elaborada aqui é a de que nenhum estudo sobre um tema tão imprevisível e cíclico (uma contradição de termos) como a pobreza pode ser conclusivo, fechado. O que proponho é que descubramos em nosso objeto o aberto, o inconstante, o contraditório. Se descobrindo isso, evidenciarmos o caminho por nós percorrido, certamente alguns problemas sociológicos desaparecerão, com felicidade. Consequentemente então, nenhuma técnica isolada é/deve ser suficientemente conclusiva, complementares, elas, produzem um efeito social sobre a opinião pública, devendo o pesquisador estar atento ao que publica e assina em tempos de "publicar ou perecer".

\section{Referências}

Bourdieu, Pierre (2007), A Distinção: crítica social do julgamento, Porto Alegre, Editora Zouk. (2003), A miséria do mundo, Petrópolis, Vozes. (1992), O Poder simbólico, São Paulo, Bertrand.

Castel, Robert (2004), La inseguridad social: ¿Que es estar protegido?, Buenos Aires, Manancial.

(1995), La metamorfoses de la question sociale: Une chronique du salariat, Paris, Fayard.

Da Matta, Roberto (1991), A Casa \& a rua: espaço, cidadania, mulher e morte no Brasil, Rio de Janeiro, Guanabara Koogan.

Fonseca, Claúdia (1999) "Quando cada caso não é um caso: a etnografia nas pesquisas em educação", Revista brasileira de educação, 10: 58-78.

Foucault, Michel (2008), O Nascimento da biopolítica, São Paulo, Martins Fontes.

Gregori, Maria Filomena (2000), Viração: experiências de meninos nas ruas, São Paulo, Companhia das Letras.

Ivo, Anete Brito Leal (2008), Viver por um fio: pobreza e política social, São Paulo, Anablüme.

Lahire, Bernard (1999), Sucesso escolar nos meios populares. As razões do improvável, São Paulo, Ática. 
Paugam, Serge (2015), A Pesquisa Sociológica, Petrópolis, Vozes.

(2005), Desqualificação social: ensaio sobre a nova pobreza, São Paulo, EDUC.

Paugam, S; Shulteis, F. (1998), "Naissance d'une sociologie de la pauvreté”, In: G. Simmel (1998), Les pauvres, Paris, Presses Universitaire de France.

Rego, Walquiria Leão; Pinzani, Alessandro (2013), Vozes do Bolsa Família: Autonomia, dinheiro e cidadania, São Paulo, Ed. Unesp.

Simmel, Georg (1998), Les Pauvres, Paris, Presses Universitaires de France.

Souza, Jessé (2009), A Ralé Brasileira Quem é e como vive, Belo Horizonte, Ed. UFMG.

Wacquant, Loïc (2011), As Prisões da Miséria, Rio de Janeiro, Zahar.

(2003), Punir os Pobres: a nova gestão da miséria nos Estados Unidos,

Rio de Janeiro, Revan.

Data de submissão: 26/02/2016 | Data de aceitação: 28/12/2016 